\title{
ALGORITHMIC OPTIMIZATION OF THE CALCULATION WITH THE CONSIDERATION OF THE INTERCONNECTION OF THE BASIC ECONOMIC PARAMETERS OF THE FLIGHT ROUTE OF THE MODEL AIR CARRIER
}

\author{
Stanislav SZABO, Monika BLISTANOVA, Sebastian MAKO, \\ Iveta VAJDOVA, Marek PILAT \\ Technical University of Kosice
}

\begin{abstract}
:
The load factor is the determining factor for airlines in economic terms and the prediction of the future development of the flight route. The combination of load factor and break-even point provides the airline with a comprehensive picture of the business of the flight route and the optimization of pricing for the flight route. The purpose of the article is to propose and adapt the development of air transport prices on a given line using maximally recalculated values and maximize profit. The optimized calculation algorithm then facilitates the understanding of the individual steps of the load factor calculation and the monitoring of price development by means of the chi-square mathematical method by which we observed the interconnection of the ticket price and the load factor. To describe the problem, we chose the Bratislava - Larnaca route.
\end{abstract}

Key words: algorithm, optimization, economic analysis, load factor

\section{INTRODUCTION}

One of the most widely used ways to determine airline pricing and profitability is the load factor. The load factor determines the aircraft utilization rate, which is the determining factor for the correct setting of pricing for the airline. The main reason for creating a scientific article is our endeavour to use algorithmic optimization in this field of research and also very low number of published scientific papers in the field. At the same time, only a limited number of authors deal with linking optimization with the load factor.

Pricing is one of the basic areas addressed by airlines, as airlines, like many other businesses, have a lot of investments and operating expenses. The aviation market has always been the center of price competition. Airline pricing has a long history, escalated mainly by deregulation of airlines in the late 1970s [16]. The process of deregulation of air transport has been linked to the process of internationalization, globalization, the expansion of freight transport and many other factors that have led to a significant increase in air passenger numbers (both private and business). All these factors have had a significant impact on the development of airline pricing strategies [6]. Airline pricing is an integral part of revenue management. The success of revenue management is based on the fact that customer segmentation and pricing blocks based on it accurately reflect current market conditions. Incorrect and inefficient revenue management practices result in poor pricing, which may result in reduced revenues and potential loss of market share [21]. The correct revenue management setting is attributed to an increase in airlines' revenues of more than $6 \%$ [22].

In this article, we also focused on the use of load factor with ticket price. To determine this relationship, we decided to use the chi-square mathematical method, which is designed to investigate the interconnection of two independent factors. Using an optimized algorithm of cost calculation, load factor, break-even point and optimized price calculation, we designed the process of pricing for transport with respect to limiting factors and total operating costs.

\section{LITERATURE REVIEW}

The load factor or, in our case, the particular passenger load factor (PLF) describes the efficiency of a particular route and is therefore one of the most widely used factors to describe the performance of the airline. High load factor is the direct indicator of the profitability of the airline and it is therefore important to monitor its development as well as the factors affecting it [12].

The load factor also has a decisive impact on the cost and quality of air transport services offered, as approximately $65 \%$ of the airline's costs are incurred in operating aircraft and based on the number of passengers carried on a particular aircraft. The high load factor means that the costs are redistributed between a sufficient number of passengers on the route, resulting in lower ticket prices [25]. 
However, a very high load factor may not always mean the profitability of an airline, especially if its revenue is low and costs are too high. On the other hand, a low load factor need not be critical if the revenue per unit sold is high. So the load factor tells you how much aircraft capacity was actually sold. It is expressed in units of passenger-kilometre [5].

Although the load factor is one of the most important factors indicating the profitability of an airline, there are disproportionately few studies on the interconnection of the load factor and economic analyses to design a specific airline's pricing. In many studies, the term load factor appears as an auxiliary variable or one of the descriptive characteristics. In most cases, the load factor is encountered in relation to the concept of air transport deregulation, where it is one of the factors compared, as is the case with Ref. [3], which analyses the merger and dominance of airlines. This is also the case, for example, in Ref. [1], [8][14] comparing the period before and after deregulation of air transport.

Pricing is given more attention than the load factor itself. Pricing research is in most cases devoted to dynamic pricing [2], [9], [13], [23], which is precisely defined in a study [26]. Research into pricing in the aerospace industry includes research by authors Ref. [18], in which the authors developed a dynamic programming formulation for revenue management based on aviation pricing. The authors show positive numerical results of the proposed pricing method in connection with revenues. Research on Ref. [11] also deals with dynamic pricing. In the framework of the research the authors consider relatively new impacts affecting revenue management of airlines such as internet distribution. The authors analyse the current features of Global distribution system - GDS and propose ways to use it to implement dynamic pricing, similar to Internet capabilities [11]. A similar issue is also dealt with in Ref. [4], which deals with Internet Price Effect (IPE), which deals with the dynamic pricing of electronic tickets. Authors Ref. [19] deals with revenue management model through optimization of fare locking options commonly offered by airlines. The authors' approach is based on the approximation of linear programming in relation to the distribution of seats during the flight and the design of a dynamic program that separately manages the capacity of each seat. Ref. [17] deals with the relationship between fare, ticket characteristics and flight load factors, thus investigating why passengers are willing to pay different prices when flying with the same airline on the same route. In the research, the authors point out the dispersion of airline prices. Pricing theory is divided into two groups. The first assumes that airlines are applying prices on the basis of scarcity and predicts that the fluctuations in ticket prices are due to differences between high demand and low demand periods. A second group of theories is that airlines practice price discrimination by using ticketing restrictions to segment customer willingness to pay [17]. In pricing, many studies are concerned with optimizing pricing based on various factors such as Ref. [7], which develops revenue optimization theory through seat inven- tory control or Ref. [24], which describes a marginal expected revenue transformation that facilitates optimization using customer selection models.

Based on the literature review we have confirmed that there is very little to no link between pricing and the load factor between the researchers analysed. The research is based on the calculation of the load factor as one of the important pricing factors.

\section{METHODOLOGY}

The article describes the development of the load factor and ticket prices and their interdependence as two factors that are crucial in the long-term planning of pricing process. Optimizing the calculation of the load factor, breakeven point and the resulting ticket price is an example of airline ticket pricing. In our case, we also designed an optimized algorithm that simplifies this process. We used real values and cost base on the Bratislava - Larnaca line for the calculation. From the airline's point of view, the above factors are crucial and their correct understanding is a fundamental determinant in airline pricing process.

\section{Load factor formula}

The load factor is calculated using the number of passengers and the seating capacity of the aircraft. This calculation gives us the percentage of aircraft utilization.

$$
\text { Load Factor }=\frac{\text { Number of passengers }}{\text { Seat load capacity of the aircraft }} \times 100 \%
$$

Chi-square is in mathematical statistics any test of statistical hypothesis, whose test criterion is assuming the validity of the null hypothesis of chi-square distribution. Often, chi-square tests appear in testing discrete distribution hypotheses where the frequency of different values of the observed traits is used.

$$
x^{2}=\sum_{i=1}^{v} \frac{\left(x_{i}+N_{p i}\right)^{2}}{N_{p i}}
$$

\section{Flight costs}

The cost of the flight is a direct expression of all the expenses associated with operating the aircraft per rotation [15]. These costs are fixed and their amount may vary only partially with the number of passengers [20], which does not affect the cost base for the calculation.

Calculated flight costs:

- Aircraft $2967 €$

- Crew $836 €$

- Maintenance $3827 €$

- Insurance $649 €$

- Fuel $6893 €$

- Navigation fees $\quad 1559 €$

- Airport fees $5000 €$

- Bus transfer $1932 €$

- Crew per diems $205 €$

- Overhead ASK $1552 €$

- Total cost $25420 €$ 
Figure 1 shows us a direct dependence of the catering price on the number of passengers. The airline has a fixed unit price for catering, which is continually increasing with the number of passengers and is therefore a variable component of the cost of the flight. Prices in the chart range from $170 €$ to $1710 €$ with 10 percent spacing.

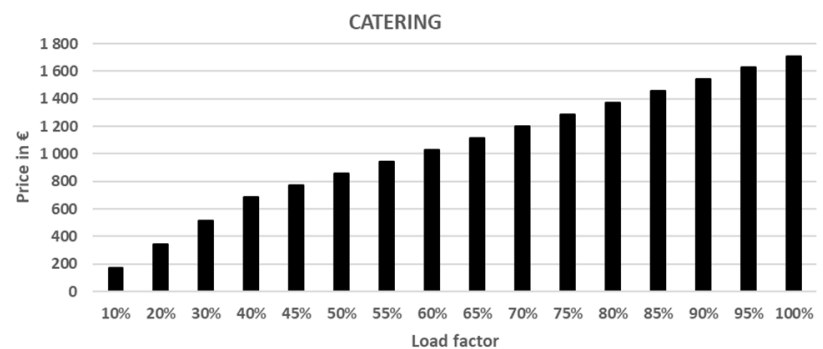

\section{Fig. 1 Catering}

Figure 2 shows a gradual increase depending on the occupancy of the route and thus on the load factor. Measuring revenue from a given flight route is an important part of the process of determining the profitability of a line and the rate of return on investment. This chart helps us identify where we reach the brake-even point and the revenue from the airline exceeds the cost of operating the above line. The graph shows revenue growth from $5773 €$ to $57730 €$ with 10 percent spacing.

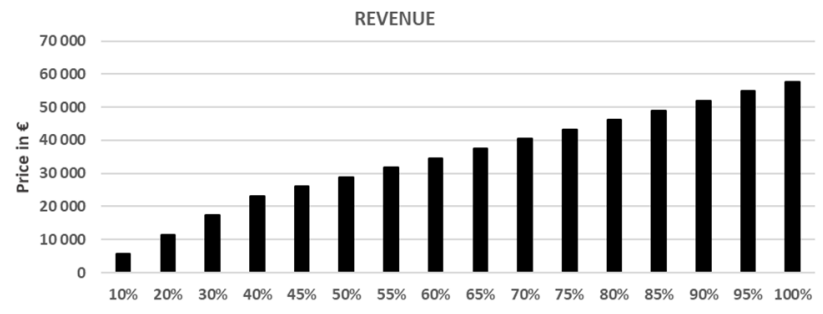

Fig. 2 Revenue

The profit or loss graph (see Figure 3) combines a gradual coverage of the cost of operating a given flight route depending on the load factor. Total costs were calculated at $25420 €$ without catering, which is a variable cost component. Break-even point is reached at $46 \%$ load factor. From this point the above line begins to be profitable. At a maximum load factor of $100 \%$, the profit is equal to $30588 €$

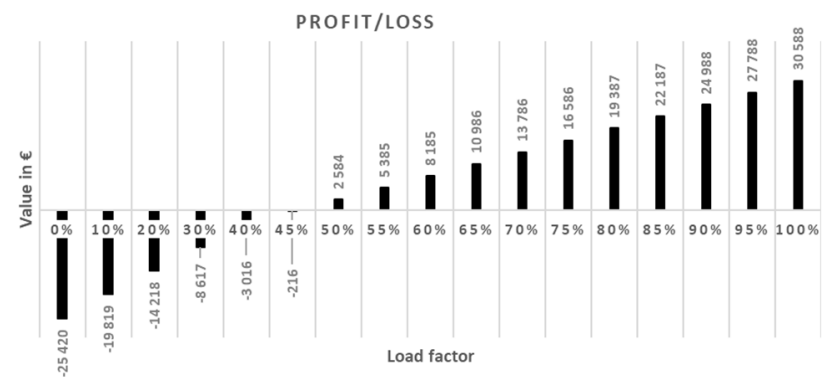

Fig. 3 Profit/Loss
Figure 4 and Figure 5 shows yield and costs per 1 passenger-kilometer. RPK - Revenue per passenger kilometer represents the average amount the passenger pays for one kilometer. The cost per passenger-kilometer starts at $0.0490 €$ and continuously increases to $0.0520 €$. Depending on the load factor, costs increase slowly and we can conclude that the difference between $10 \%$ and $100 \%$ load factor in terms of cost per passenger-kilometer is not great. Revenue/Yield per 1 passenger-kilometre starts at $0.0111 €$ and rises to $0.1106 €$. Revenue growth is much faster than cost. The operation of the line becomes profitable at a load factor of $46 \%$, and line reaches brake-even point when revenue per 1 passenger-kilometre is 0.0509 $€$ which exceeds the cost per 1 passenger-kilometre are $0.0502 €$. The ideal situation is always $100 \%$ load factor where revenues $0.1106 €$ more than double the costs $0.0520 €$

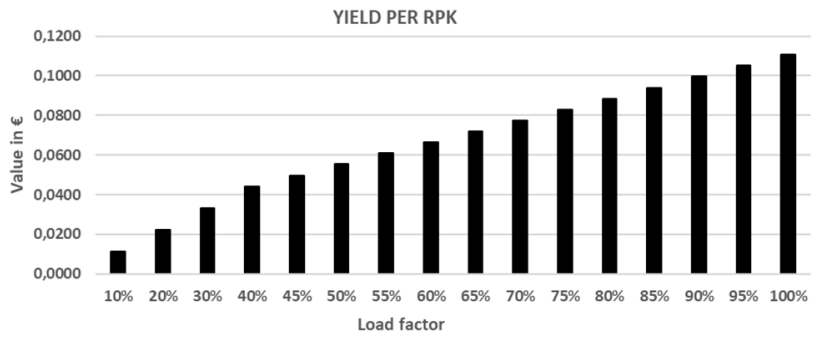

Fig. 4 Yield per RPK

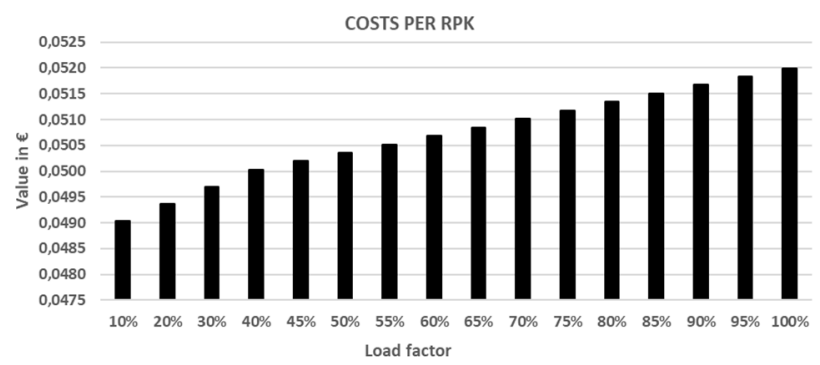

Fig. 5 Costs per RPK

Figure 6 shows the percentage of operating profit on the Bratislava - Larnaca route. This graph increases by 10 percent and the lowest point of the graph with a load factor of $10 \%$ can be seen loss calculated at $343.36 \%$. Break-even point occurs at a load factor of $46 \%$. At this point, the operating profit is equal to $1.30 \%$. The ideal situation is a load factor of $100 \%$, with an operating profit of $52.99 \%$.

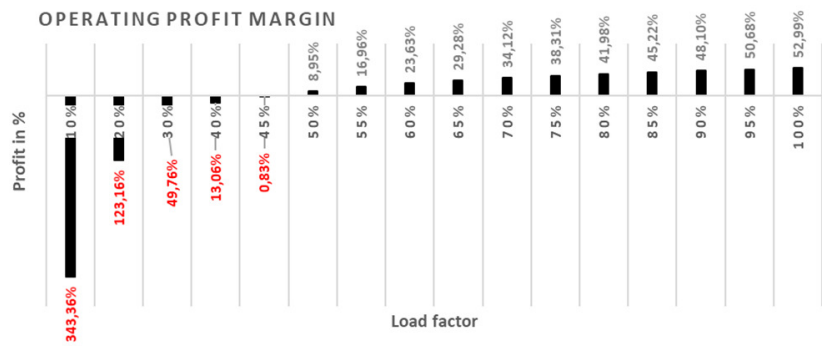

Fig. 6 Operating margin profit 


\section{RESULTS}

The goal of optimization of the cost calculation for a given flight was to analyse the partial costs constituting the cost basis of the flight. Based on these parameters, an applied break-even point parameter has been defined based on which the airline can built pricing policy.

\section{Break-even point}

The break-even point represents the sales amount - in either unit (quantity) or revenue (sales) terms - that is required to cover total costs, consisting of both fixed and variable costs to the company. Total profit at the breakeven point is zero. It is only possible for a firm to pass the break-even point if the value of sales is higher than the variable cost per unit. In our case the achievement of break-even point is directly dependent on the load factor, which must reach at least $46 \%$.

Brake-even point key indicators:

$\begin{array}{lr}\text { - Total costs } & 25420 € \\ \text { - Catering } & 788 € \\ \text { - Revenue } & 26551 € \\ \text { - Profit } & 344 € \\ \text { - Yield pre RPK } & 0.0509 € \\ \text { - Costs per RPK } & 0.0502 € \\ \text { - Operating profit margin } & 1.30 \%\end{array}$

Figure 7 shows us the development of the price for transport, which is influenced by the load factor on the given line. The price starts at $217 €$ at which point the aircraft is loaded to a maximum of $10 \%$. Slight price development is characterized up to the break-even point when the aircraft load is equal to $46 \%$. From this point onwards the price becomes more pronounced ascending. The most significant differences are between the $80 \%$ load factor where the price is $695 €$ and the $100 \%$ load factor in the price of $2062 €$. This price range is based on the pricing policy of this flight route.

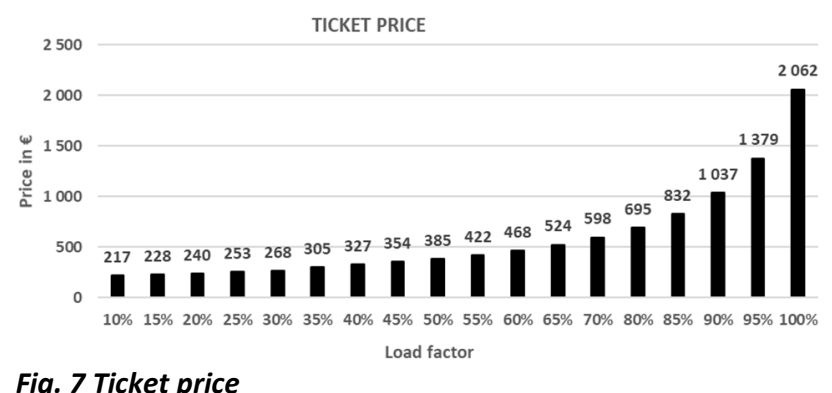

Algorithm A1 is used to calculate Catering, Basic costs and Total revenue and is not optimized (see Figure 8). Algorithm $A 1$ has a number of unknowns $A_{1}-A_{9}$, which are constants and thus it is easier to express them through the variable $B_{c}$ - Basic costs. In addition, the algorithm does not take into account the variable Total income, which is more important for the airline than Total Revenue. Algorithm A2 is more complex and optimized for calculating not only Total Income but also calculating the Load Factor correlation and ticket price (see Figure 8).
The A2 algorithm offers more outputs at fewer inputs than $\mathrm{A} 1$ and is optimized for use on flight route.
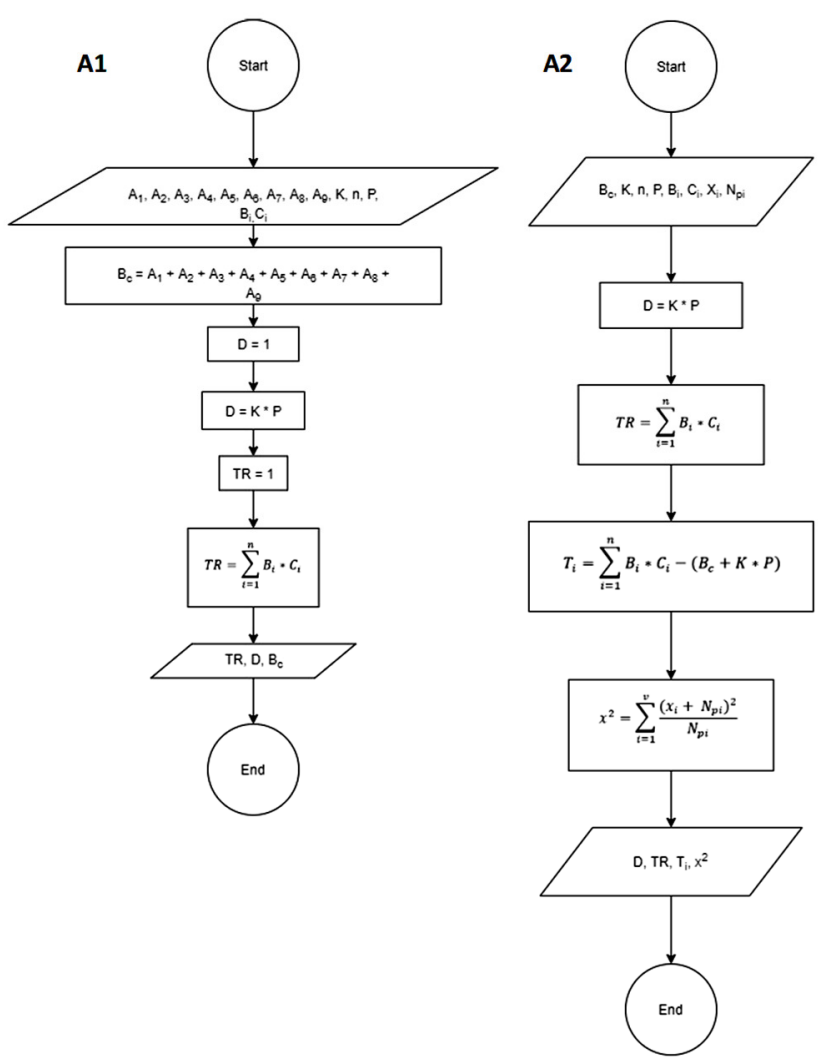

Fig. 8 Algorithms A1 and A2

List of variables:

$A_{1}$ - aircraft costs, $A_{2}$ - crew costs, $A_{3}$ - maintenance, $A_{4}$ - insurance, $A_{5}$ - fuel, $A_{6}$ - navigation fees, $A_{7}$ - airport fees, $A_{8}-$ bus transfer, $A_{g}$ - overhead ASK, $B_{c}$ - basic costs, $D$ - catering, $K$ - unit price per catering, $P$ - number of passenger, $T R$ - total revenue, $n$-number of blocks, $B_{i}-$ block seats, $C_{i}-$ block price, $T_{i}$ - total income

By analysing this data, we found a significant impact of the load factor on the ticket price. This effect is shown by a graph (Figure 7) where it can be seen that the price rises with the load of the aircraft. For the mathematical rationale of this analysis we used chi-square. Chi-square calculation is in our case combining ticket price and load factor via calculation of expected and real value (see Table 1). This calculation focuses on the interconnection of the load factor and the ticket price to answer the question whether the two variables are interdependent or not. The expected value describes the expected value of the tickets sold and the real value describes the actual value of the tickets sold and their dependence on the load factor.

Based on the chi-square calculation, we verified the hypothesis that we say that at the significance level $\alpha=5 \%$ we are using the formula for the calculation of chi-square calculated a total chi $=0.999999998$. This value confirms the hypothesis, there is a strong interconnection between the load factor and the ticket price. Another suggestion is to use an optimized algorithm to calculate individual unknowns such as total income. 
Table 1

Input values for chi-square calculation

\begin{tabular}{ccc}
\hline Ticket price (in $€$ ) & Expected value (in \%) & Real value (in \%) \\
\hline 2062 & 19 & 5 \\
1379 & 13 & 5 \\
1037 & 10 & 5 \\
832 & 8 & 5 \\
695 & 7 & 5 \\
598 & 6 & 10 \\
524 & 5 & 5 \\
468 & 4 & 5 \\
422 & 4 & 5 \\
385 & 4 & 5 \\
354 & 3 & 5 \\
327 & 3 & 5 \\
305 & 3 & 5 \\
268 & 3 & 5 \\
253 & 2 & 5 \\
240 & 2 & 5 \\
228 & 2 & 5 \\
217 & 2 & 10 \\
Total & $100 \%$ & $\mathbf{1 0 0 \%}$ \\
\hline
\end{tabular}

\section{DISCUSSION}

One of the important factors of the airline's economic analysis is the load factor. Load factor and break-even point are the determining factors in the process of determining the profitability of the line and lead the company to optimize the pricing policy based on these parameters. The general procedure for calculating the load factor and some economic parameters is shown in the following algorithms. The process of optimizing algorithms is as important as using them due to the fact that an incorrectly determined algorithm does not provide us the required data. We used chi-square calculation to determine interconnection between load factor and the ticket price. As stated above in literature review none of authors used interconnection of load factor and ticket price via chi square calculation in pricing policy of airlines. Contribution of using this method is based on a strong correlation of the parameters used, thereby optimizing the currently used pricing policy of airlines.

\section{CONCLUSION}

Defining an effective Pricing policy is one of the most important and demanding activities of airlines. A well-defined pricing policy helps the airline effectively manage its profitability. Airlines use individual methods to define pricing policy parameters. Based on an analysis of domestic and foreign scientific papers, we found that airlines pay more attention to pricing policy than the load factor and do not link load factor with pricing policy. Most airlines currently use dynamic pricing policy $[2,9,13,23,26]$. In this research we use the parameter load factor to define pricing policy.

The load factor is one of the basic factors influencing the economic analysis of the airline and its subsequent optimization, especially in terms of pricing and pricing policy options available to the air carrier at that time. In our case we chose the Bratislava - Larnaca route. The graphs describe the development of costs and revenues of the above-mentioned airline. Another area we dealt with was the creation of an optimized algorithm for calculating the key economic parameters of the airline. This algorithm serves as a general guide and can be applied to any flight route. We examined the interconnection of the ticket price and the load factor using the chi square mathematical method. This mathematical method examines the correlation of two independent variables. In our case, the result of this analysis is a strong correlation of the abovementioned factors and thus the factors are interdependent.

\section{REFERENCES}

[1] B. H. Baltagi, J. M. Griffin, D. P. Rich, „Airline Deregulation: The Cost Pieces of the Puzzle, "International Economic Review, Vol. 36, No. 1 (Feb., 1995), pp. 245-258 DOI: $10.2307 / 2527435$.

[2] P. Belobaba, L. R. Weatherford, „Comparing Decision Rules that Incorporate Customer Diversion in Perishable Asset Revenue Management Situations, " Decision Sciences Journal, Vol. 27, Issue2, 1996, pp. 343-363, DOI https://doi.org/10.1111/j.1540-5915.1996.tb00856.x.

[3] S. Borenstein, „Airline Mergers, Airport Dominance, and Market Power," American Economic Review, 1990, vol. 80, issue 2, pp. 400-404.

[4] W. G Brunger, „The impact of the Internet on airline fares: The 'Internet Price Effect', "Journal of Revenue and Pricing Management, Vol. 9, Issue 1-2, 2010, pp. 66-93, DOI https://doi.org/10.1057/rpm.2009.35.

[5] R. Doganis, "Flying Off Course IV: Airline Economics and Marketing " $4^{\text {th }}$ edition, 2010, Taylor\&Francis e-library.

[6] L.. Fedorco, J. Hospodka, „Airline pricing strategies in european airline market," Perner's Contacts, Vol. VIII, No 2, 2013.

[7] T. Fiig, K. Isler, C. Hopperstad, P. Belobaba, „Optimization of mixed fare structures: Theory and applications," Journal of Revenue and Pricing Management, Vol. 9, Issue 1-2, 2010, pp. 152-170, DOI https://doi.org/10.1057/rpm.2009.18.

[8] D. R. Graham, D. P. Kaplan, D. S. Sibley, „Efficiency and Competition in the Airline Industry," The Bell Journal of Economics, Vol. 14, No. 1 (Spring, 1983), pp. 118-138 DOI: $10.2307 / 3003541$.

[9] Z. Guo et al., „,Research on dynamic pricing model of electronic airplane ticket in electronic commerce," Control and Decision Conference - CCDC 2009, Chinese, 2009.

[10] P. Hanák, et al., "The analysis of the price trend of low-cost carriers in Slovakia," Transport means 2018. Part I, 2018, pp. 347-350.

[11] K. Isler, E. D'Souza, "GDS capabilities, OD control and dynamic pricing," Journal of Revenue and Pricing Management, Vol. 8, Issue 2-3, 2009, pp. 255-266, DOI https://doi.org/10.1057/rpm.2008.57.

[12] N.A. Ismail, H. S. Jenatabadi, "Determination of Load Factors in the Airline Industry", Fifth International Business Research Conference, Strands of Development, 2007, Dubai, United Arab Emirates.

[13] M. Kelemen, et al., "Pricing Policy Aspects in Competitive Fight Between Low-Cost Airlines on Kosice Airport," Journal of KONBiN: The Journal of Air Force Institute of Technology, Vol. 49, 2019, Issue 1, pp. 331-342.

[14] D. J. Lloyd-Jones, „Deregulation and Its Potential Effect on Airline Operations," Journal of Air Law and Commerce, Vol. 41, 1975, Issue 4, [Online]. Available on: ttps://scholar.smu.edu/jalc/vol41/iss4/13. 
[15] M. Mačej, "Lowering the costs by applying optimised Cost Index," Transport Means, 2018. Part 3, 2018, pp. 13791382.

[16] S. Poelt, „Practical Pricing and the Airline Industry” Revenue Management, 2011, DOI https://doi.org/10.1057/9780230294776_15.

[17] S. L. Puller, A. Sengupta, S. N. Wiggins, „Testing Theories of Scarcity Pricing in the Airline Industry, "National Bureau of Economic Research, 2009 DOI: 10.3386/w15555 https://www.nber.org/papers/w15555.pdf.

[18] A.M. Selcuk, Z.M. Avsar, „Dynamic pricing in airline revenue management," Journal of mathematical analysis and applications, Vol. 478, 2019, Issue: 2, pp. 1191-1217, DOI: 10.1016/j.jmaa.2019.06.012.

[19] M. Sumida, H. Topaloglu, „Approximation Algorithm for Capacity Allocation Over a Single Flight Leg with Fare-Locking," Informs journal on computing, Vol. 31, 2019, Issue: 1, pp. 83-99, DOI: 10.1287/ijoc.2018.0816.

[20] S. Szabo, et al., "Optimization of the parameters of aircraft ground handling by cost function" CEFE2017, 2017 pp. 733-739.

[21] B. Vinod, „The complexities and challenges of the airline fare management process and alignment with revenue management," Journal of Revenue and Pricing Management, Vol. 9, Issue 1-2, 2010, pp. 137-151, DOI https://doi.org/10.1057/rpm.2008.43.

\author{
Stanislav Szabo \\ ORCID ID: 0000-0001-6174-5784 \\ Technical University of Kosice \\ Faculty of Aeronautics \\ Department of Air Transport Management \\ Rampova 7, 04121 Kosice, Slovak Republic

\section{Monika Blistanova} \\ ORCID ID: 0000-0561-2568-2900 \\ Technical University of Kosice \\ Faculty of Aeronautics \\ Department of Air Transport Management \\ Rampova 7, 04121 Kosice, Slovak Republic
}

\section{Sebastian Mako}

ORCID ID: 0000-0001-9220-1771

Technical University of Kosice

Faculty of Aeronautics

Department of Air Transport Management Rampova 7, 04121 Kosice, Slovak Republic

\section{Iveta Vajdova}

ORCID ID: 0000-0002-1231-8492

Technical University of Kosice

Faculty of Aeronautics

Department of Air Transport Management Rampova 7, 04121 Kosice, Slovak Republic e-mail: iveta.vajdova@tuke.sk

\section{Marek Pilat}

ORCID ID: 0000-0002-2526-6556

Technical University of Kosice

Faculty of Aeronautics

Department of Air Transport Management Rampova 7, 04121 Kosice, Slovak Republic
[22] D. Walczak, E. A. Boyd, R. Cramer, „Revenue Management," Quantitative Problem Solving Methods in the Airline Industry, pp. 101-161 DOI https://doi.org/10.1007/978-1-4614-1608-1_3.

[23] D. Walczak, S. Brumelle "Semi-Markov information model for revenue management and dynamic pricing," OR Spectrum, Vol. 29, Issue 1, 2007, pp. 61-83, DOI https://doi.org/10.1007/s00291-005-0026-z.

[24] D. Walczak, S. Mardan, R. Kallesen „Customer choice, fare adjustments and the marginal expected revenue data transformation: A note on using old yield management techniques in the brave new world of pricing," Journal of Revenue and Pricing Management, Vol. 9, Issue 1-2, 2010, pp. 94-109 DOI https://doi.org/10.1057/rpm.2009.38.

[25] J.G. Wensveen, A.T. Wells, „Air Transportation: A Management Perspective“, $6^{\text {th }}$ edition, 2007, Ashgate Publishing Company.

[26] M.D. Wittman, P.P. Belobaba, P.P., „Dynamic pricing mechanisms for the airline industry: a definitional framework," Journal of Revenue and Pricing Management, Vol. 18, 2019, Issue 2, pp. 100-106 DOI: https://doi.org/10.1057/s41272-018-00162-6. 